\title{
Correction to: Spatio-temporal Change of Glacier Surging and Glacier-dammed Lake Formation in Karakoram Pakistan
}

\author{
Javed Akhter Qureshi ${ }^{1}$ (1) Garee Khan ${ }^{1} \cdot$ Nauman Ali $^{1} \cdot$ Sajid Ali $^{1}$. Shams ur Rehman ${ }^{2} \cdot$ Razia Bano $^{3} \cdot$ Sajjad Saeed $^{4,5}$. \\ Muhammad Azhar Ehsan ${ }^{6}$
}

(c) King Abdulaziz University and Springer Nature Switzerland AG 2021

\section{Correction to: Earth Systems and Environment https://doi.org/10.1007/s41748-021-00264-z}

Unfortunately, the third affiliation "Department of Business Management, Karakoram International University, Gilgit, 15100 , Pakistan" is published in the original publication with all coauthors but it is only with Razia Bano. Authors would like to correct the third affiliation.

We regret the inconvenience caused.

The original article has been updated.

The original article can be found online at https://doi.org/10.1007/ s41748-021-00264-z.

Javed Akhter Qureshi

javed.akhter@kiu.edu.pk

Muhammad Azhar Ehsan

azhar@iri.columbia.edu

1 Department of Earth Sciences, Karakoram International University, Gilgit 15100, Pakistan

2 Department of Mathematics, Karakoram International University, Gilgit 15100, Pakistan

3 Department of Business Management, Karakoram International University, Gilgit 15100, Pakistan

4 Earth System Physics Section, The Abdus Salam International Centre for Theoretical Physics (ICTP), Trieste, Italy

5 Department of Earth and Environmental Sciences, University of Leuven (KU Leuven), Leuven, Belgium

6 International Research Institute for Climate and Society, Earth Institute at Columbia University, Palisades, NY, USA 